\title{
RANCANG BANGUN APLIKASI GAME DEKSTOP LOKAL BANJARMASIN POMA 3D GAME ADVENTURE MENGGUNAKAN UNITY GAME ENGINE
}

\author{
Zayid Musiafa, S.Kom, M.Kom \\ Fakultas Teknologi Informasi \\ Universitas Islam Kalimantan Muhammad Arsyad Al Banjari Banjarmasin \\ zayidmusiafa.fti@gmail.com
}

\begin{abstract}
ABSTRAK
Bangsa Indonesia memiliki banyak kepulauan dan bentang geografis yang beragam, diiantaranya Kalimantan. Kota Banjarmasin adalah ibu kota provinsi Kalimantan Selatan, Indonesia. Banjarmasin yang dijuluki Kota Seribu Sungai ini memiliki wilayah seluas $98,46 \mathrm{~km}^{2}$ yang wilayahnya merupakan delta atau kepulauan. Memiliki budaya sungai dengan interaksi masyarakat yang sangat kuat terhadap sungai baik dalam kegiatan sosial maupun ekonomi. Saat ini, game merupakan media hiburan yang memanfaatkan tekhnologi. Game di Indonesia sendiri sedang banyak diminati para remaja. Game yang ada semakin canggih dan menarik. Karena menariknya gama-game sekarang mayoritas memiliki tujuan sebagai media hiburan saja, sedangkan untuk game yang memiliki tujuan hiburan serta mengandung edukasi lokal hanya sedikit.

Oleh sebab ulasan diatas maka perlu dibuatlah sebuah game bertama lokal. Gagasan rancang bangun aplikasi permainan dekstop lokal banjarmasin poma $3 \mathrm{~d}$ game adventure menggunakan unity game engine ini berstoryline mengeksplor sedikit hal yang menarik dari lingkup kota Banjarmasin seperti mengangkat beberapa ciri khas (ikon) atau kegiatan yang dekat dengan kehidupan masyarakat kota Banjarmasin dari permainan game tersebut diharapkan dapat memberikan kontribusi positif sebagai media mengenalkan potensi daerah secara universal.
\end{abstract}

Kata Kunci : A Star, Game, Unity, 3d, Game Engine, 3Ds Max, Lokal Banjarmasin.

\section{PENDAHULUAN}

Bangsa Indonesia memiliki banyak kepulauan dan bentang geografis yang beragam, diiantaranya Kalimantan. Kota Banjarmasin adalah ibu kota provinsi Kalimantan Selatan, Indonesia. Banjarmasin yang dijuluki Kota Seribu Sungai ini memiliki wilayah seluas $98,46 \mathrm{~km}^{2}$ yang wilayahnya merupakan delta atau kepulauan yang terdiri dari sekitar 25 buah pulau kecil (delta) yang dipisahkan oleh sungai-sungai di antaranya pulau Tatas, pulau Kelayan, pulau Rantauan Keliling, pulau Insan dan lain-lain ("Banjarmasin Ternyata Kepulauan", 2011). Mayoritas penduduk kota Banjarmasin berasal dari etnis Banjar (79,26\%). Penduduk asli yang mendiami Banjarmasin adalah orang Banjar Kuala yang memiliki budaya sungai dengan interaksi masyarakat yang sangat kuat terhadap sungai baik dalam kegiatan sosial maupun ekonomi. Hal ini dapat diihat dari adanya Pasar Terapung yang menjadi salah satu objek wisata 
andalan Kota Banjarmasin. Di Banjarmasin juga banyak terdapat orang Banjar Pahuluan yang berasal dari Banua Anam serta orang Banjar dari daerahdaerah lain di Kalimantan Selatan

. Game yang ada semakin canggih dan menarik. Karena menariknya gamagame sekarang mayoritas memiliki tujuan sebagai media hiburan saja, sedangkan untuk game yang memiliki tujuan hiburan serta mengandung edukasi lokal hanya sedikit.

Oleh sebab ulasan diatas maka perlu dibuatlah sebuah game bertama lokal. Game ini berstoryline mengeksplor sedikit hal yang menarik dari lingkup kota Banjarmasin seperti mengangkat beberapa ciri khas (ikon) atau kegiatan yang dekat dengan kehidupan masyarakat kota Banjarmasin.

\section{RUMUSAN MASALAH}

Berdasarkan latar belakang tersebut diawal, maka perumusan masalah berupa gagasan rancang bangun aplikasi permainan dekstop lokal banjarmasin poma $3 \mathrm{~d}$ game adventure menggunakan unity game engine. Game ini berstoryline hal yang menarik dari lingkup Kota Banjarmasin seperti mengangkat beberapa ciri khas atau kegiatan yang dekat dengan kehidupan masyarakat Kota Banjarmasin.

\section{TUJUAN PENELITIAN}

Tujuan penelitian ini adalah untuk mengembangkan suatu aplikasi permainan dekstop bahan media hiburan, edukasi dan pengenalan potensi sosial budaya dari deaerah banjarmasin berbasis teknologi informasi digital media mengenalkan potensi daerah secara universal.

\section{TARGET LUARAN DAN MANFAAT PENELITIAN}

Target luaran dalam pembuatan laporan penelitian ini diharapkan dapat memberikan kontribusi positif sebagai media mengenalkan potensi daerah. Publikasi ilmiah jurnal lokal yang memiliki ISSN atau jurnal nasional terakreditasi seperti jurnal Al Ulum Universitas Islam Kalimantan (UNISKA) MAAB.

Manfaat dari penelitian memberikan alternatif hiburan melalui game yang diciptakan dan berusaha agar game yang sajikan tidak "monoton" karena mengangkat tema lokal. Dari permainan game tersebut diharapkan dapat memberikan kontribusi positif untuk mengenalkan potensi daerah secara universal.

\section{METODE PENELITIAN}

\section{Analisis Sistem}

Analisis sistem merupakan penguraian dari suatu sistem yang utuh ke dalam bagian-bagian komponennya dengan maksud untuk mengidentifikasi dan mengevaluasi permasalahan-permasalahan,

kesempatan-kesempatan, hambatanhambatan yang terjadi dan kebutuhankebutuhan yang diharapkan sehingga dapat diusulkan perbaikan-perbaikan. Analisis merupakan tahapan yang paling penting, karena kesalahan dalam tahap ini akan menyebabkan kesalahan di tahap selanjutnya. Dari hasil analisis tersebut dapat dirancang atau diperbaiki menjadi sebuah sistem yang lebih efektif dan efisien. Pada tahap analisis sistem ini dibagi menjadi beberapa bagian, yaitu sebagai berikut :

\subsection{Analisis Masalah}

Analisis masalah adalah langkah awal dari analisis sistem. Langkah ini 
diperlukan untuk mengetahui pemasalahan apa saja yang terjadi didalam sistem yang telah berjalan. Berdasarkan studi pustaka yang telah dilakukan dengan membaca penelitianpenelitian terdahulu, terdapat masalah yang diangkat sebagai dasar pembangunan aplikasi game yang akan dibangun yaitu minimnya dan belum ada sumber dan produk digital tentang aplikasi game lokal kota banjarmasin.

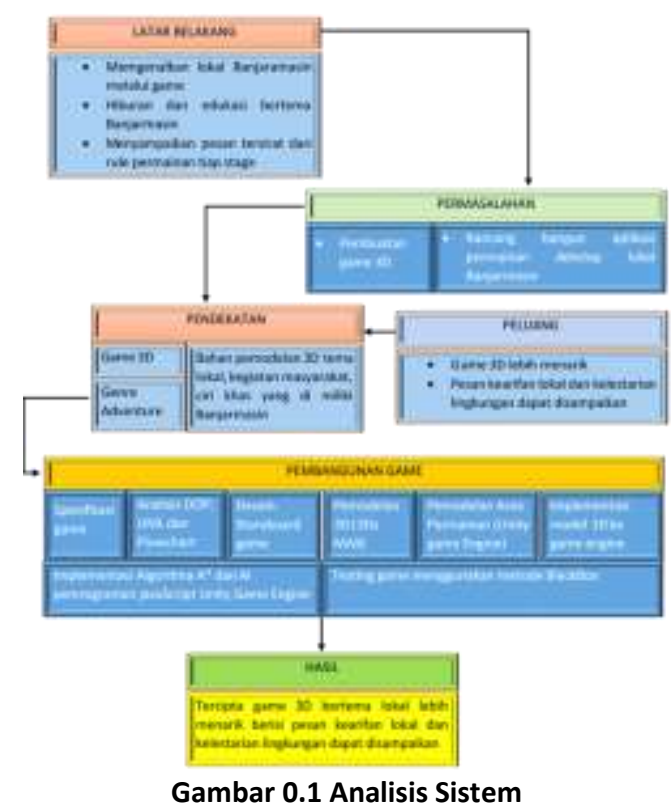

\section{Analisis Kebutuhan dan Perancangan Sistem}

Merancang program dengan menentukan spesifikasi game yaitu game dekstop, melakukan analisis berorientasi objek menggunakan UML adalah menentukan aktor atau pengguna sistem. Kata aktor dalam konteks UML, menampilkan peran (roles) pengguna atau sesuatu diluar sistem yang dikembangkan yang dapat berupa perangkat keras, end user, sistem yang lain, dan sebagainya.

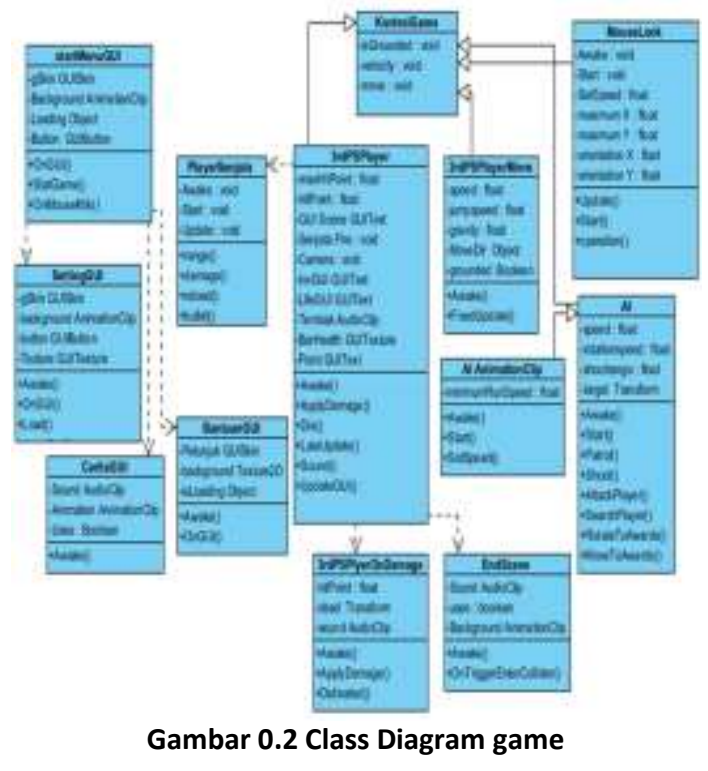

Secara khusus Flowchart diperlukan guna memberi deskripsi lebih mendalam tentang proses sebuah scene yang terbentuk dengan korelasi storyboard game.

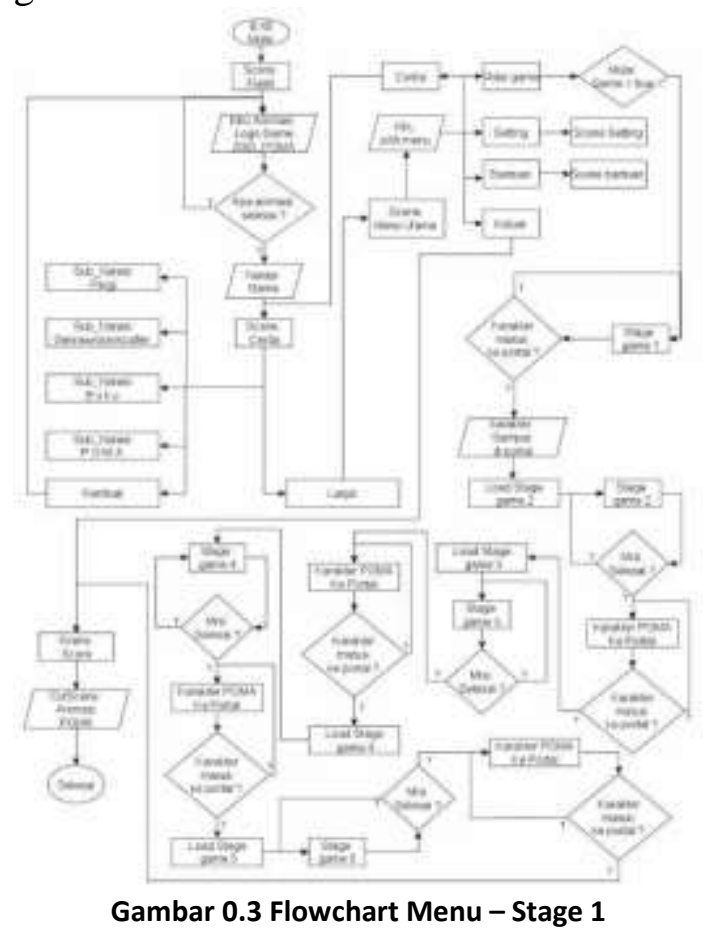




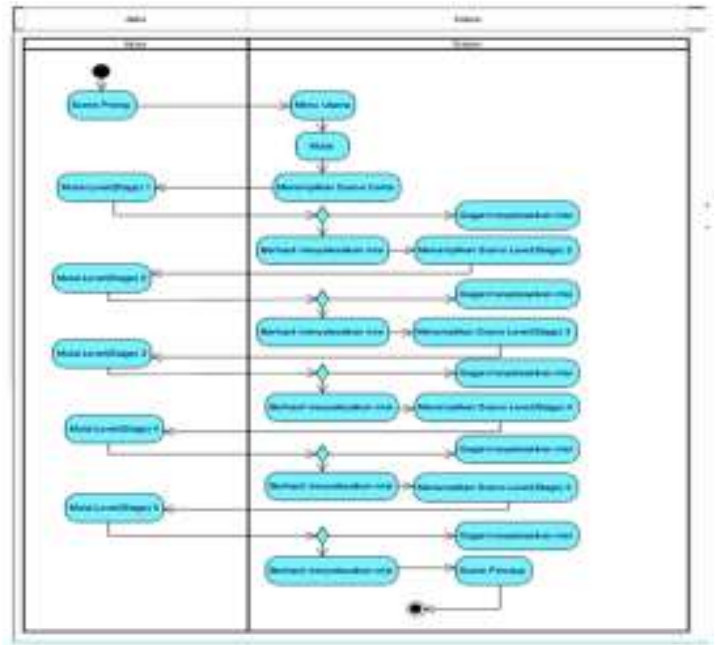

Gambar 0.4 Activity Diagram game

\section{Pembuatan Program}

Mengimplementasikan

hasil rancangan ke perangkat lunak untuk pemodelan $3 \mathrm{~d}$ yang digunakan adalah 3Ds Max.

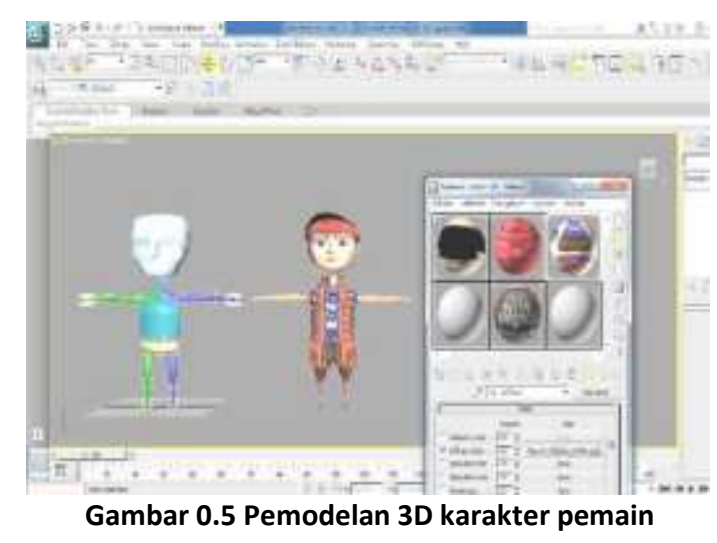

Sedangkan game engine yang dipadukan menggunakan Unity 3D.

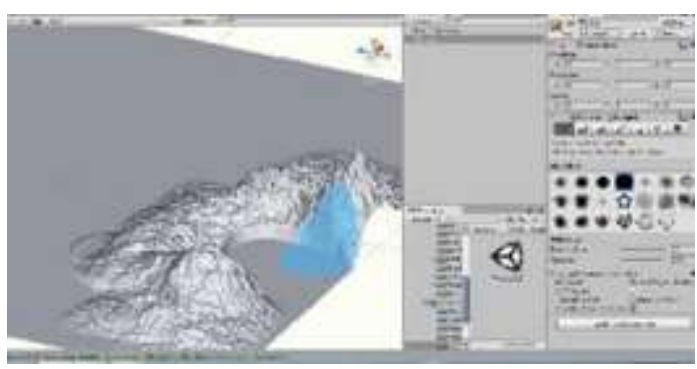

Gambar 0.6 Pemodelan Terrain

Bahasa pemrograman menggunakan JavaScript di Unity Editor dan penerapan
Algortima A Star (A*) untuk Objek game; enemy.

\section{Pengujian Program}

Percobaan untuk menjalankan permainan yang telah dibuat apakah sesuai dengan yang diinginkan. Menguji dan menganalisis program menggunakan pendekatan metode BlackBox.

\section{HASIL DAN PEMBAHASAN}

\section{Interface Menu Permainan}

Saat permainan dijalankan akan muncul tampilan awal berupa menu utama dan ketika event klik pada masing masing tombol diklik maka akan muncul tampilan menu sesuai dengan kondisi dan fungsi tombol yang di pilih.

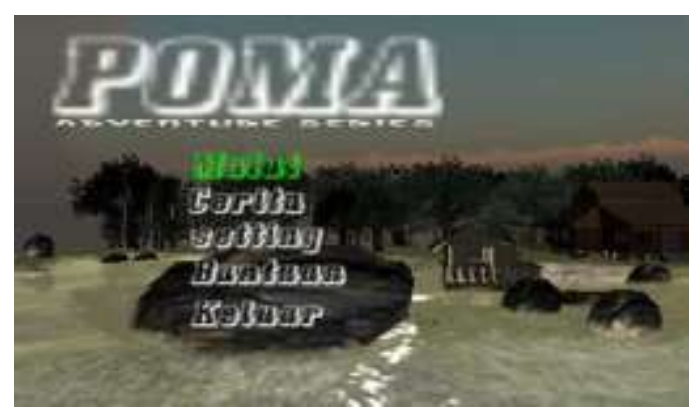

Gambar 0.7 Menu Utama

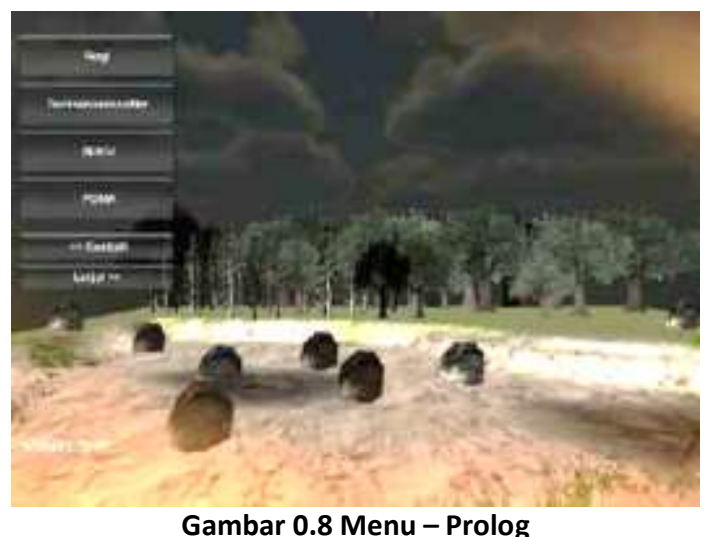

Gambar 0.8 Menu - Prolog 


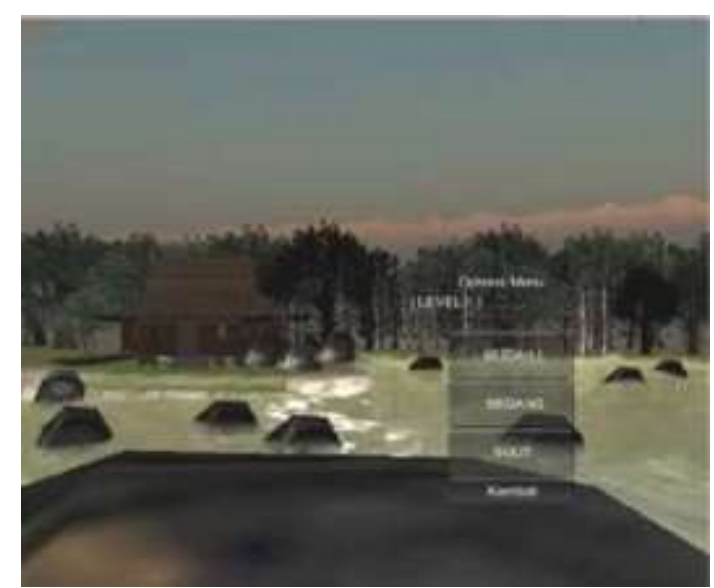

Gambar 0.9 Menu - Setting Level

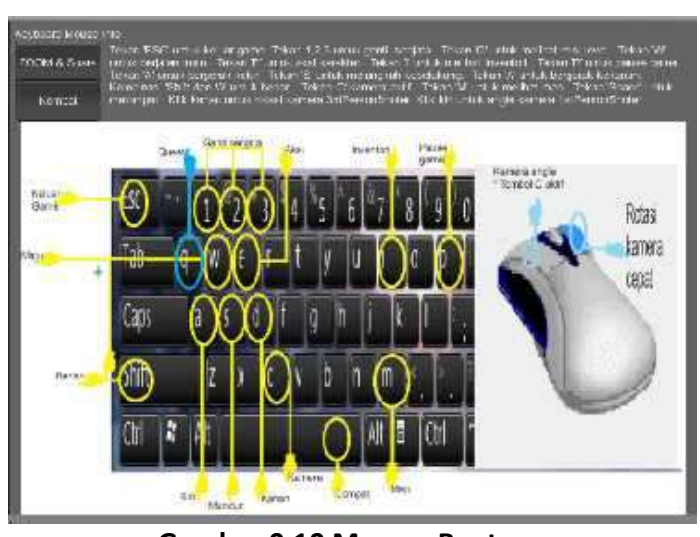

Gambar 0.10 Menu - Bantuan

Berikut ini tampilan cut scene tiap-tiap stage permainan;

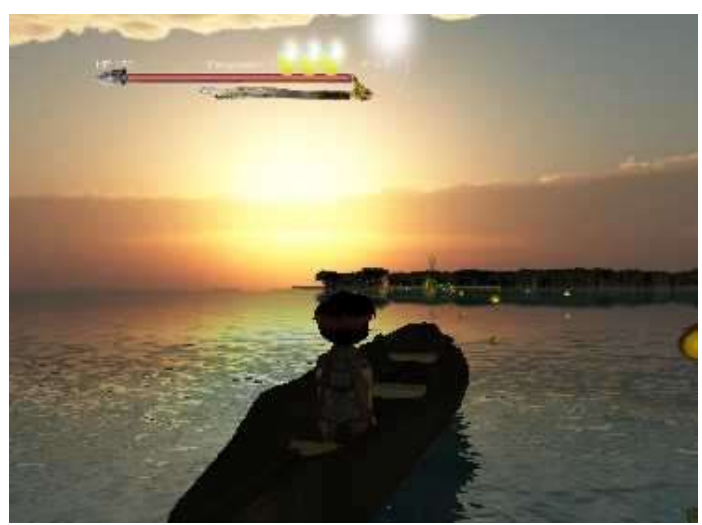

Gambar 0.11 Cut Scene Permainan Stage 1

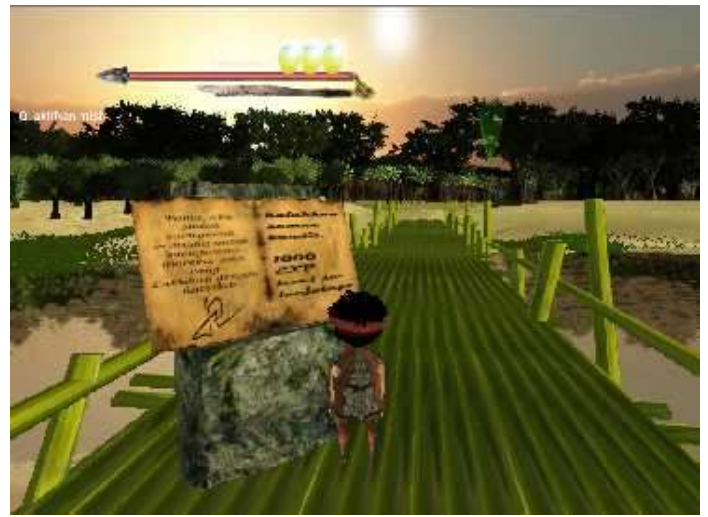

Gambar 0.12 Cut Scene Permainan Stage 2

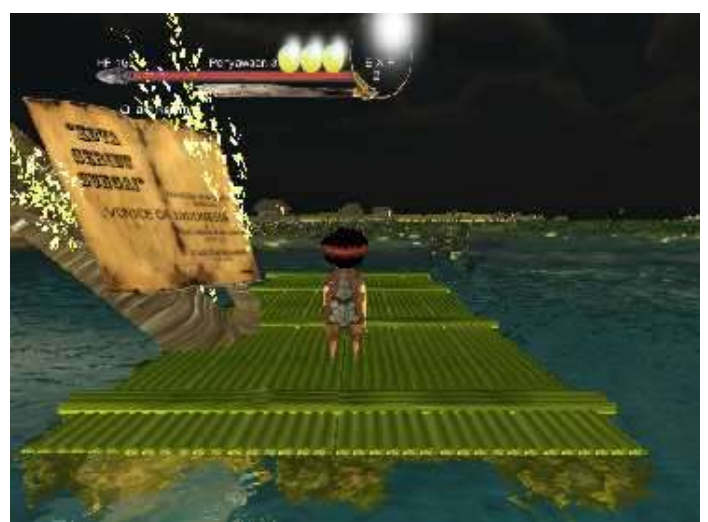

Gambar 0.13 Cut Scene Permainan Stage 3

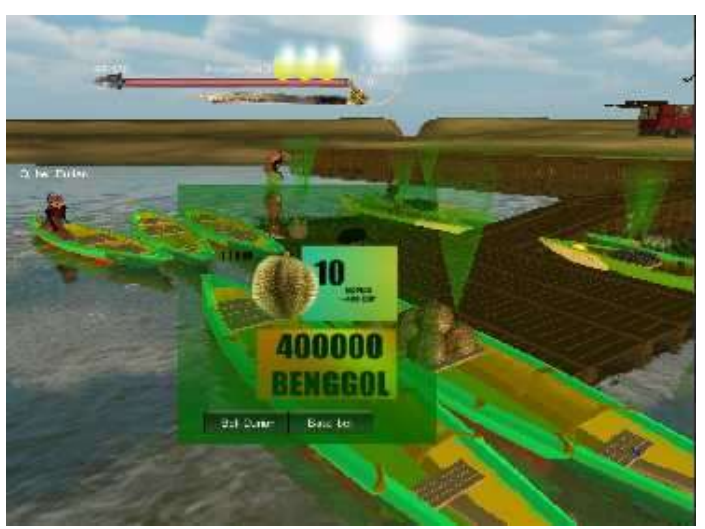

Gambar 0.14 Cut Scene Permainan Stage 4

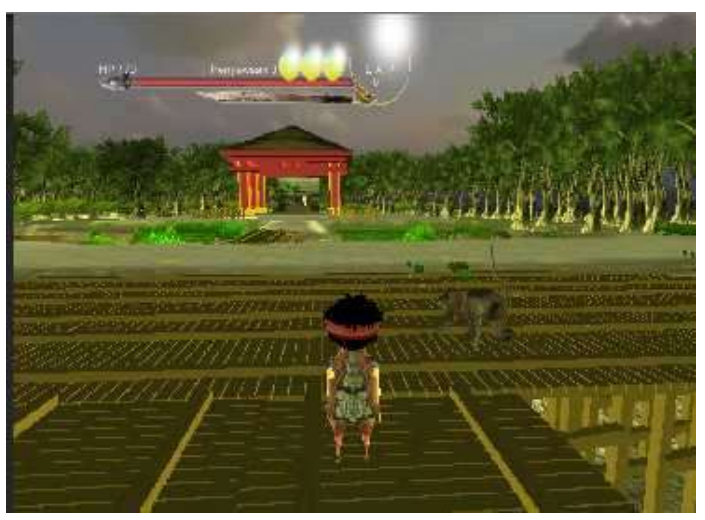

Gambar 0.15 Cut Scene Permainan Stage 5 


\section{PENUTUP}

\section{Kesimpulan}

Berdasarkan hasil penelitian dan pembahasan di penelitian ini, maka dapat kesimpulkan diantaranya;

1. Dari komposisi cerita, visualisasi gambar dan efek audio masih belum maksimal ketika menggunakan laptop dengan kelas low entry.

2. Game ini menjadi media penyampaian pesan moral melalui dialog karakter dalam game.

3. Durasi permainan dari awal hinggal akhir menyelesaikan lima stage game tidaklah banyak menyita waktu sehingga pada game ini bisa dijadikan hiburan alternatif.

\section{Saran}

Pembuatan game ini belum sempurna, sehingga diharapkan nantinya dalam pengembangan game berikutnya lebih sempurna sehingga bisa menceritakan semua maksud dari game dengan baik. Adapun beberapa hal yang menjadi saran bagi penelitian lanjutan dalam pengembang game ini, antara lain:

1. Game ini dapat dikembangkan pada penambahan level dan tingkat kesulitan disetiap levelnya(AI).

2. Penambahan plot dan cutscene game sehingga memperkuat unsur cerita.

3. Modeling 3D menggunakan texturing yang lebih menarik sehingga menyerupai keadaan yang sebenarnya.

4. Menambahkan nilai karakteristik tempat bahkan unsur sejarah.

5. Permainan masih berbasis dekstop awalnya dapat dikembangkan sesuai dengan pangsa pasar misal support device VR, berbasis Web, Android, dan Real Time Simulasi.

\section{DAFTAR PUSTAKA}

"Banjarmasin Ternyata Kepulauan". (2011, August 8). Retrieved from http://www.radarbanjarmasin.co.i d/index.php/berita/detail/36/8275

Aguilera, M. D., \& Mendiz, A. (2003, October). Video Games and Education (Education in the Face of parallel School). ACM Computers in Entertainment Vol 1 Article 01.

Akilli, G. K. (2007). Games and Simulations : A New Approach in Education?Pennsylvania: Information Science Publishing.

Blackman, S. (2011). Beginning 3D Game Development with Unity. Apress.

Bourgh, D.M. \& Seemann, G. (2004). AI for Game Developers. USA: O'Reilly Media.

Butler-Purry, K., Pedersen, S., \& Srinivasan, V. (2008). Using Video Games to Enhance Learning in Digital Systems. In FuturePlay (pp. 196-199).

Fullerton, Tracy dkk. (2004). Game Design Workshop: Designing, Prototyping, and Playtesting Games. US: Elsevier Inc.

Helgason, david, Ante, Joachim dkk. (n.d.). 3D Platformer Tutorial 
Building a 3D Platform Game in Unity 2.0. US.

IAN Somerville. (2002). Rekayasa Perangkat Lunak. Jakarta: Alex Media Komputindo.

Pedersen E. Roger. (2002). Game Design Foundations. Wordware Publishing Inc.
Sismoro, H. (2005). Pengantar Logika Informatika, Algoritma, dan Pemrograman Komputer. Yogyakarta: Andi Offset. 